\title{
PENYULUHAN HUKUM MENGENAI KETERTIBAN BERLALU LINTAS DIKAJI DARI ASPEK PERATURAN PERUNDANG-UNDANGAN NOMOR 22 TAHUN 2009 TENTANG LALU LINTAS DAN ANGKUTAN JALAN BAGI PELAJAR SMA SEKOLAH YAYASAN PENDIDIKAN HARAPAN 3 KOTA MEDAN
}

\author{
Fajar Khaify Rizky ${ }^{1}$, D. Shahreiza ${ }^{2}$,M. Din Al Fajar ${ }^{3}$, Boy Laksamana $^{4}$, Amsali Syahputra S $^{5}$ \\ ${ }^{1,2,3,4)}$ Fakultas Hukum, Universitas Sumatera Utara \\ e-mail: fajarkhaifirizki89@gmail.com
}

\begin{abstract}
Abstrak
Di dalam Undang-Undang Nomor 22 Tahun 2009 tentang Lalu Lintas dan Angkutan Jalan mendefinisikan lalu lintas sebagai gerak kendaraan dan orang di ruang lalu lintas jalan, sedangkan yang dimaksud dengan ruang lalu lintas jalan adalah prasarana yang diperuntukkan bagi gerak pidah kendaraan, orang, dan/atau barang yang berupa jalan dan fasilitas pendukung. Bertujuan untuk mewujudkan lalu lintas dan angkutan jalan yang selamat, aman, cepat, lancar, tertib dan tertatur, nyaman dan efisien melalui manajemen lalu lintas dan rekayasa lalu lintas. Lalu lintas dan angkutan jalan mempunyai peran yang cukup penting dalam rangka pembangunan pada umumnya untuk tercapainya kesejahteraan masyarakat sebagaimana diamanatkan UUD 1945. Sehubungan dengan itu maka kegiatan atau aktivitas berlalu lintas dan pengangkutan di jalan raya harus diatur hukum agar tercipta ketertiban dan keamanan sesuai dengan Undang-Undang Nomor 22 Tahun 2009 tentang Lalu Lintas dan Angkutan Jalan. Kegiatan pengendalian lalu lintas meliputi: 1. Pemberian arahan dan petunjuk dalam pelaksanaan kebijaksanaan lalu lintas, berupa penetapan atau pemberian dan tata cara untuk keperluan pelaksaan manajemen lalu lintas dengan maksud agar diperoleh keseragaman dalam pelaksanaannya serta dapat dilaksanakan sebagaimana mestinya untuk menjamin tercapainya tingkat pelayanan yang telah ditetapkan. 2. Pemberian bimbingan dan penyuluhan kepada masyarakat mengenai hak dan kewajiban masyarakat dalam pelaksanaan kebijakan lalu lintas. Adapun sanksi hukum akan dilihat dari jenis pelanggaran yang dilakukan oleh pelaku. Dalam pengabdian masyarakat ini metode yang dipergunakan adalah dengan observasi, pemaparan, dan diskusi.
\end{abstract}

Kata Kunci: Aspek Hukum Lalu Lintas dan Angkutan Jalan, Tujuan, Sanksi Hukum.

\begin{abstract}
In Law Number 22 of 2009 concerning Road Traffic and Transportation defines traffic as the movement of vehicles and people in the road traffic space, while what is meant by road traffic space is infrastructure intended for the movement of vehicles, people, and/or vehicles. or goods in the form of roads and supporting facilities. Aims to realize safe, safe, fast, smooth, orderly and orderly, comfortable and efficient traffic and road transportation through traffic management and traffic engineering. Road traffic and transportation have a fairly important role in the framework of development in general for the achievement of public welfare as mandated by the 1945 Constitution. In this regard, traffic and transportation activities on roads must be regulated by law in order to create order and security in accordance with the Act. Law Number 22 of 2009 concerning Road Traffic and Transportation. Traffic control activities include: 1. Providing directions and instructions in the implementation of traffic policies, in the form of stipulation or giving and procedures for the purposes of implementing traffic management with the aim of obtaining uniformity in its implementation and can be carried out properly to ensure the achievement of the level of service that has been set. set. 2. Providing guidance and counseling
\end{abstract}


to the community regarding the rights and obligations of the community in implementing traffic policies. The legal sanctions will be seen from the type of violation committed by the perpetrator. In this community service the method used is observation, presentation, and discussion.

Keywords: Traffic and Road Transportation Legal Aspects, Objectives, Legal Sanctions.

\section{PENDAHULUAN}

Budaya tertib berlalu lintas masyarakat di Indonesia masih memprihatinkan. Berdasarkan data Korps Lalu lintas Polri, angka kecelakaan sebanyak 105.374 kejadian dengan 22.939 jiwa meninggal dunia, atau rata-rata tiga orang meninggal setiap jam. Dilihat dari segi usia, korban didominasi usia 15-19 tahun (sebanyak 29.654 jiwa). Sementara, 36.541 orang (44,27 persen) pelaku kecelakaan lalu lintas tidak memiliki SIM. Terbanyak pelanggar lalu lintas adalah anak muda atau pelajar. "Mereka memang bisa berkendara tapi secara mental, psikologis belum cukup dewasa untuk berinteraksi di jalanan. Sehingga menyebabkan banyak kecelakaan. Demi menekan angka korban kecelakaan lalu lintas, Polri menggandeng kemendikbud untuk mendidik anak disiplin dasar berlalulintas sejak dini. (Pewarta Medan.com, 2019).

Korlantas sudah membuat kesepakatan bersama (MoU) dengan Kemendikbud untuk memasukkan pendidikan disiplin dasar berlalu lintas dalam kurikulum pendidikan. "Melalui kurikulum yang dimasukkan ke dalam mata pelajaran PKn ini, guru-guru bisa membantu pelajar agar sadar berlalu lintas. Melalui kesepakatan itu, diharapkan para guru PPKn dapat mengajarkan pendidikan keselamatan berlalu lintas kepada anak didik agar saat mereka dewasa nanti, menjadi pelopor tertib berlalu lintas. Dalam pelaksanaannya, guru dapat melibatkan polisi terdekat untuk berbagi pengetahuan terkait disiplin dasar berlalu lintas. "Hal ini dapat dilakukan melalui pendidikan secara formal dan informal. Kegiatan formal meliputi menyediakan bahan agar keselamatan berlalu lintas di setiap tingkat pendidikan formal, melaksanakan MoU". (Pewarta Medan.com, 2019).

Ops Zebra yang dilakukan selama 14 hari mulai dari 23 Oktober sampai 5 November 2019, Polda Sumut mencatat 53.659 kendaraan melakukan pelanggaran.Dari jumlah tersebut, sebanyak 43.245 kendaraan di antaranya ditilang, sedangkan 10.414 kendaraan lainnya mendapatkan sanksi teguran. (Tribun Medan.com, 2019).

Dirlantas Polda Sumut Kombes Pol Kemas Ahmad Yamin mengatakan dibandingkan dengan Ops Zebra 2018, operasi ini mengalami peningkatan 5 persen untuk kendaraan yang melakukan pelanggaran, yakni 51.265 perkara. Sedangkan perkara tilang hanya naik $1 \%$ atau dari 42.821 kendaraan pada tahun lalu, dan perkara teguran naik $23 \%$ atau dari 8.444 perkara. Orang nomor satu di Ditlantas Polda Sumut ini menyatakan sebanyak 43.245 kendaraan yang ditilang, paling banyak kendaraan yang ditilang adalah roda dua dengan 32.267 unit. Sedangkan untuk mobil penumpang sebanyak 5.370 unit, mobil barang 4.035 unit, mobil bus 1.566 unit dan kendaraan khusus sebanyak 7 unit. Untuk sepeda motor pelanggaran terbanyak seperti tidak menggunakan helm SNI, surat-surat, hingga melawan arus dan berkendara dibawah umur. Sedangkan pada mobil dan kendaraan khusus di dominasi surat-surat, tidak menggunakan safety belt, hingga menggunakan HP saat berkendara. (Tribun Medan.com, 2019).

Untuk kecelakaan lalulintas yang terjadi saat Ops Zebra Toba 2019, Polda Sumut mencatat sebanyak 98 kejadian. Dari jumlah tersebut 32 orang meninggal dunia, 24 orang luka berat, dan luka ringan sebanyak 134 orang. Dibandingkan tahun lalu, jumlah kecelakaan mengalami kenaikan $26 \%$ atau dari 78 kejadian. Untuk korban meninggal dunia terjadi penurunan, di mana pada tahun 2018 ada 44 orang, luka berat 36 orang dan luka ringan 85 orang. Melihat angka pelanggaran naik 5 persen dari tahun sebelumnya. Ini berarti masih banyak masyarakat yang belum peduli terhadap keselamatan saat berkendara. Sementara, dari pihak Ditlantas Polda Sumut sudah berulang kali mengingatkan dan membuat spanduk maupun baliho terkait upaya agar para pengendara melengkapi surat-surat dan mengutamakan 
keselamatan. Sudah kita buat imbauan baik dari baliho, media cetak dan online serta sosialisasi ke masyarakat umum dalam mengikuti peraturan rambu lalu lintas. (Tribun Medan.com, 2019).

\section{PERMASALAHAN MITRA}

Dari berbagai daerah dilaporkan, pelajar mendominasi pelanggaran dalam Operasi Zebra tahun ini. Di Kabupaten Deli Serdang, misalnya, Operasi Zebra 2019 menindak 5.494 pelanggar lalu lintas. Dari jumlah itu sebanyak 4.175 adalah pelajar mereka umumnya berkendaraan sepeda motor. Pelanggaran yang paling banyak dilakukan, adalah: Tidak punya SIM (Surat Izin Mengemudi), tidak membawa Surat Tanda Nomor Kendaraan (STNK), dan tidak memakai helm. Realita hasil Operasi Zebra 2019, ini juga layak menjadi kajian bagi pemerintah di daerah, khususnya menyangkut kebijakan transportasi dan letak sekolah. Pemerintah daerah bisa menginisiasi angkutan sekolah. Yang ideal memang seperti di kota besar yang ada bis sekolah. Bila pun tidak memungkinkan, aturan rute angkutan umum harus mempertimbangkan keberadaan sekolah. Kebijakan yang lain adalah menyangkut keberadaan fisik bangunan sekolah. Sekolah menengah sudah selayaknya di bangun di wilayah-wilayah pemekaran kabupaten dan kota, tak bisa lagi hanya terpusat di perkotaan. Banyaknya pelajar yang terjaring Operasi Zebra di daerah menjadi fenomena yang mengkhawatirkan, sebab hal serupa sudah terjadi dalam beberapa tahun terakhir. Pihak kepolisian pun sudah berusaha untuk menihilkan pelanggaran lalu lintas oleh pelajar.

Polda Sumut misalnya sejak beberapa waktu lalu, aktif mendatangi sekolah, untuk mengimbau agar murid yang belum memiliki SIM dilarang mengendarai sepeda motor ke sekolah. Ketentuan kepemilikan SIM, mengharuskan usia minimum adalah 16 tahun. Batasan itu setara dengan usia pelajar antara kelas 11 dan 12. Namun di lapangan yang terjadi pelajar SMP pun sudah mengendarai sepeda motor untuk ke sekolah. Ketentuan batasan umur untuk mendapatkan SIM tersebut, punya alasan sangat mendasar. Pada usia tersebut, seseorang dinilai sudah bisa mengontrol emosinya, sehingga pada usia tersebut seseorang bisa memiliki ketrampilan, pengetahuan, dan kemampuan berkendara secara baik. Orang tua, pada umumnya tahu bahkan memberi izin--anaknya mengendarai sepeda motor, sekali pun tidak memiliki SIM karena memang belum berusia 16. Artinya orang tua memberi andil dalam pelanggaran undang-undang yang dilakukan anaknya. Jarak dan langkanya kendaraan umum menuju sekolah yang dijadikan alasan orang tua untuk mengizinkan anaknya bersepeda motor ke sekolah. Selain tentu saja kondisi ekonomi orang tuanya yang mampu membelikan sepeda motor untuk anaknya. Sikap orang tua yang seperti ini yang semestinya dikoreksi. Memberikan fasilitas sepeda motor kepada anak yang belum layak bermotor, sama halnya mendorong anak untuk melakukan pelanggaran hukum. Dan itu tentu saja sangat berbahaya bagi sang anak. Bukan saja anak akan menjadi permisif terhadap pelanggaran, tapi juga potensi membahayakan fisik anak. Kecelakaan misalnya. Orang tua semestinya meluangkan waktu mengantar dan menjemput sekolah. Bila tidak memungkinkan, bisa saja memikirkan alternatif kendaraan bagi anaknya untuk ke sekolah. Sepeda bisa jadi pilihan, apa lagi sekarang sepeda listrik (Selis) sudah banyak pilihan di pasar. Untuk jarak tempuh $10-15 \mathrm{~km}$, mengendarai Selis sangat memungkinkan, tidak melelahkan, dan waktu tempuh pun bisa kurang dari 1 jam, mengingat kecepatan Selis bisa mencapai 20$25 \mathrm{~km}$ per jam.

Pihak sekolah pun semestinya lebih tegas dalam memberlakukan larangan bersepeda motor ke sekolah bagi muridnya. Pelanggaran lalu lintas memang masuk dalam kategori tindak pidana ringan (tipiring). Pidananya pun selesai ketika hukuman denda dilunasi. Dan tidak ada sebutan residivis, bagi pelaku pelanggaran lalu lintas yang berulang. Namun membiarkan anak melakukan pelanggaran lalu lintas, sama halnya dengan mendidik anak untuk tidak taat hukum. Meski berbagai aturan sudah dikeluarkan untuk membuat situasi lalu lintas tetap kondusif, pada kenyataannya masih saja banyak pengguna jalan yang tidak mengindahkan aturan-aturan tersebut.

Meski berbagai aturan sudah dikeluarkan untuk membuat situasi lalu lintas tetap kondusif, pada kenyataannya masih saja banyak pengguna jalan yang tidak mengindahkan aturan-aturan tersebut. 
Berbagai pelanggaran kerap dilakukan. Ironisnya, kelalaian tersebut tak jarang merugikan orang lain. Seringkali terjadi kecelakaan yang membuat orang lain terluka atau bahkan tewas.

\section{METODE}

Metode yang dipergunakan dalam kegiatan ini adalah dengan observasi, pemaparan, dan diskusi terarah yang diawali dengan pemaparan tentang penyuluhan dengan substansi hukum terhadap aspek hukum berlalu lintas dan selanjutnya dilanjutkan dengan tanya jawab antara penyuluh dengan guru sekolah dan siswa-siswi, terutama untuk lebih memperjelas substansi penyuluhan. Melalui penyuluhan dan pemaparan dapat disampaikan materi-materi yang penting untuk diketahui oleh guru, siswa-siswi sekolah. Tanya jawab dapat melengkapi materi yang belum jelas dan diketahui oleh warga sekolah serta untuk memberikan masukan atas permasalahan yang dihadapi dalam pelaksanaan kegiatan pengabdian ini.

\section{HASIL DAN PEMBAHASAN}

Dalam kegiatan ini para peserta penyuluhan atau siswa-siswi dapat memahami tujuan kegiatan penyuluhan ini yaitu dari norma-norma peraturan mengenai lalu lintas, aspek penegakan kepatuhan, keselamatan, dan ketertiban dalam berlalu lintas berdasarkan peraturan perundang-undangan no. 22 tahun 2009 tentang lalu lintas dan angkutan jalan.

Tujuan dari pelaksanaan kegiatan pengabdian ini adalah untuk meningkatkan kesadaran akan pentingnya keamanan, keselamatan, ketertiban dan kelancaran dalam berlalu lintas khususnya bagi siswa atau pelajar SMA Sekolah Yayasan Pendidikan Harapan 3 Kota Medan. Dan tujuan dari aspek penegakan kepatuhan, keselamatan dan ketertiban berlalu lintas berdasarkan Peraturan Perundang-Undangan Nomor 22 Tahun 2009 tentang Lalu Lintas dan Angkutan Jalan.

Di samping itu, capaian dari pelaksanaan kegiatan pengabdian ini adalah peningkatan kesadaran akan pentingnya keamanan, keselamatan, ketertiban, dan kelancaran berlalu lintas bagi siswa atau pelajar SMA Sekolah Yayasan Pendidikan Harapan 3 Kota Medan.

Dalam kegiatan pengabdian ini diawali dengan kata sambutan dari kedua belah pihak, yakni dari pihak Yayasan Pendidikan Harapan oleh Pengurus Yaspendhar 3, Bapak Muslim Harahap dan kemudian dibuka oleh Kepala Sekolah SMA, Bapak Abdul Jalil, MS. Dan selanjutnya dari kami tim penyuluh dan pelaksana kegiatan pengabdian dari pihak perwakilan Fakultas Hukum Universitas Sumatera Utara, Medan yang hadir kesemuanya pada hari pelaksanaan yang berjumlah 5 (lima) orang.

Selanjutnya kegiatan tersebut dilanjutkan dengan kata sambutan oleh Ketua Pengabdian Bapak Fajar Khaify Rizky, SH., MH, dan kemudian pemaparan yang disampaikan oleh Bapak Amsali Putra Sembiring, SH., M.Hum kepada para peserta yang berjumlah 11 (sebelas) siswa dan siswi SLTA Yayasan Pendidikan Harapan 3. Diwakilkan oleh 3 (tiga) orang siswi dan 8 (delapan) orang siswa selama lebih kurang 1,5 (satu setengah) jam dengan sumber bahan yang telah kami sediakan sebelumnya. Setelah pemaparan tersampaikan selanjutnya diadakan sesi diskusi dan tanya jawab oleh peserta dan tim penyuluh secara terbuka dengan cara bergantian. Sesi ini disambut dengan antusiasme yang cukup tinggi dari para siswa dilihat dari separuh peserta yang mengajukan pertanyaan kepada kami pihak penyuluh mengenai ketertiban berlalu lintas yang dikaji dari aspek peraturan perundang-undangan nomor 22 tahun 2009 tentang lalu lintas dan angkutan jalan. 


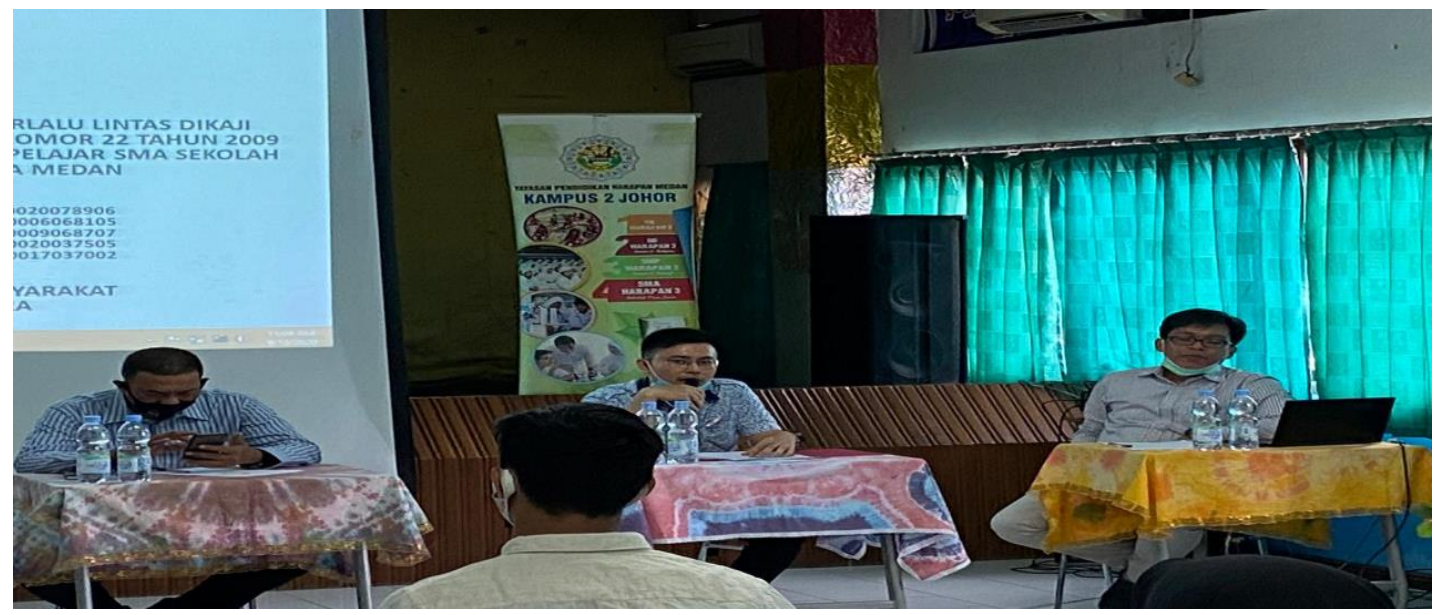

Gambar 1. Ketua Tim Pengabdian Memberikan Kata Sambutan

Kegiatan awal yang dilakukan oleh tim pengabdian adalah melakukan penyuluhan hukum tentang ketertiban berlalu lintas dari aspek undang-undang lalu lintas yang dilakukan secara interaktif antara penyuluh dengan siswa-siswi dan pihak sekolah terkait. Adapun metodologinya kami melakukan pemaparan melalui slide power point ditunjang dengan media-media penunjang lain (infokus, laptop, dll). Kemudian dilakukan diskusi tanya jawab oleh peserta, dalam hal ini siswa-siswi terpilih yang berjumlah sebanyak 11 orang dengan didampingi oleh kepala sekolah, wakil kepala sekolah dan pengurus Sekolah Yayasan Pendidikan Harapan 3 Kota Medan.

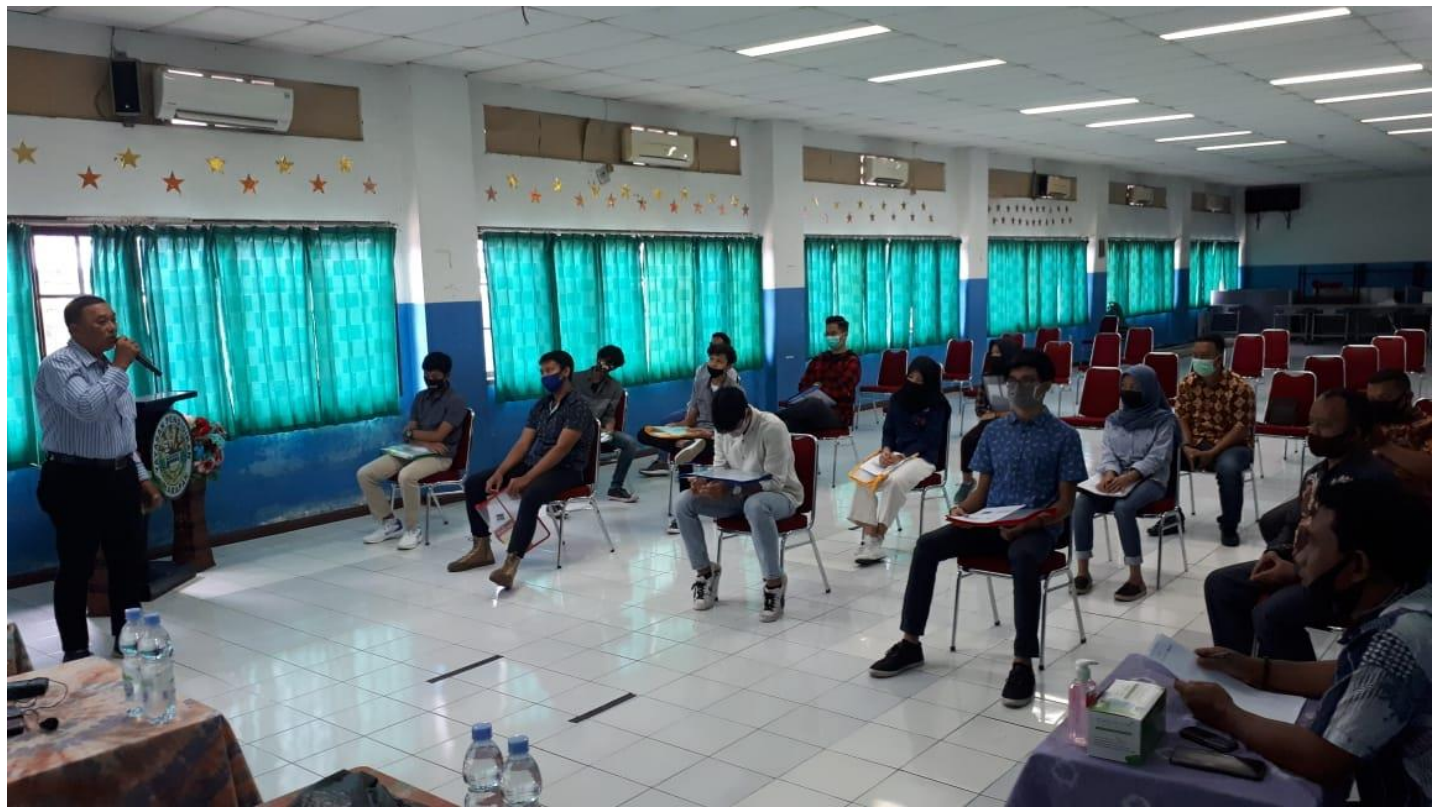

Gambar 2. Anggota Tim Pengabdian Memberikan Pemaparan Materi 
Kegiatan ini mendapat perhatian yang cukup luar biasa bahkan diluar perkiraan kami sebelumnya, dimana pihak sekolah dan para peserta yang dalam hal ini mengikuti kegiatan tersebut, mendapat perhatian penuh dan sangat antusias dalam mengikuti penyuluhan yang kami sampaikan.

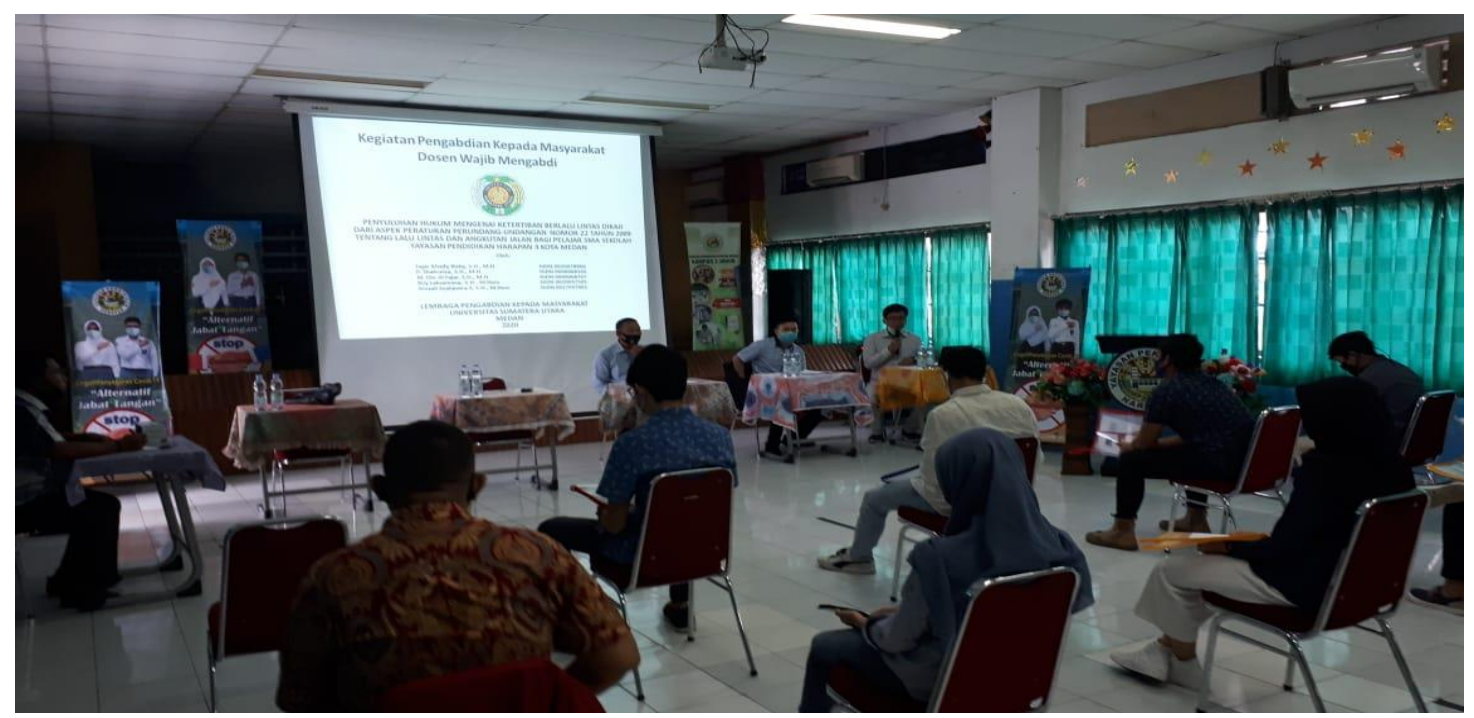

Gambar 3. Antusias Peserta Kegiatan Pengabdian Kepada Masyarakat

Adapun permasalahan yang dialami siswa-siswi dan guru yang dituangkan dalam pertanyaan sebagai berikut:

1. Apa yang dimaksud dengan kecelakaan tunggal?

2. Apakah ada SIM khusus untuk penyandang disabilitas?

3. Mengapa kendaraan roda dua diharuskan menyalakan lampu pada siang hari?

Berdasarkan pertanyaan di atas, kami tim berdiskusi untuk menghasilkan jawaban sebagai berikut:

1. Kecelakaan tunggal merupakan yang tidak berbenturan dengan kendaraan lain. Dalam arti kecelakaan tersebut hanya menyebabkan kerugian dari satu pihak yang tidak merugikan pihak lain. Dalam kecelakaan tunggal ini dilihat juga hal yang terjadi kepadanya dapat berupa luka ringan, luka berat maupun kehilangan nyawa. Hal tersebut disebabkan karena faktor kelelahan, kelalaian, faktor alam, maupun kendaraan yang tidak layak.

2. Ada yaitu SIM D. SIM D ini diperuntukkan bagi mereka yang mengemudikan kendaraan khusus bagi penyandang disabilitas. SIM D ini sengaja dibuat bagi pengendara yang memiliki keterbatasan atau berkebutuhan khusus yang ingin mengendarai kendaraan, prosedurnya sama seperti SIM lainnya, bedanya kendaraan yang digunakan adalah kendaraan khusus dan harus melalui ujian teori dan dua ujian praktik, ujian lapangan dan ujian di jalan raya. Selama penyandang disabilitas tersebut bisa mengemudi ranmor yang bukan kategori kendaraan khusus penyandang disabilitas, maka diperbolehkan untuk itu keselamatan berkendara merupakan hak bersama, termasuk bagi penyandang disabilitas.

3. Menyalakan lampu di siang hari selain untuk menjaga keselamatan berkendara, nyala lampu sepeda motor tersebut akan menjadi penanda keberadaan kita, sehingga pengguna jalan lain dapat waspada 
dalam mengemudi sehingga kecelakaan lalu lintas dapat dihindarkan. Bagi pengendara motor yang tidak menyalakan lampu di siang hari dikenakan denda atau dipidana kurungan paling lama 15 hari dan dianggap melanggar Pasal 293 ayat (2) UU. No. 22 Tahun 2009 yang berbunyi: "Setiap orang yang mengemudikan sepeda motor di jalan tanpa menyalakan lampu utama pada siang hari sebagaimana dimaksud dalam Pasal 107 ayat (2) dipidana dengan pidana kurungan paling lama 15 hari atau denda paling banyak Rp.100.000,-. Dengan demikian jelas tertulis bila menyalakan lampu depan motor di siang hari menjadi kewajiban bagi pengendara motor di Indonesia.

\section{KESIMPULAN}

Berdasarkan hasil kegiatan pengabdian ini, maka kami dapat menarik tiga kesimpulan yaitu sebagai berikut yang pertama Bahwa banyak pengguna kendaraan kurang menyadari akan pentingnya keselamatan, ketertiban serta kelengkapan berkendara dalam sehari-hari. Kedua Bahwa keselamatan dalam berkendara dilihat dalam dua sisi yang berdampingan dan tidak dapat dipisahkan, yaitu dari sisi pengguna jalan raya dan sisi pemakai kendaraan di jalan raya. Yang diantara keduanya masing-masing memiliki hak dan kewajiban yang sama. Ketiga Bahwa pentingnya Peraturan Perundang-Undangan No. 22 Tahun 2009 Tentang Lalu Lintas dan Angkutan Jalan perlu disosialisasikan secara berkala dan permanen khususnya bagi pengguna jalan dan kendaraan di tingkat awal usia produktif, dari tingkatan smp, sma dan perguruan tinggi.

\section{DAFTAR PUSTAKA}

Chrysnanda Dwi Laksana, Hukum dan Penegakkan Hukum Lalu Lintas, Suara Karya, 2018.

Danu Anindito dan Ira Alya Maerani, Kebijakan Hukum Terhadap Pelanggaran Lalu Lintas Oleh Anak, Jurnal Hukum Khaira Ummah Vol. 13, No. 1, Maret 2018.

Sudjana, Penyuluhan Hukum Dalam Upaya Peningkatan Kesadaran Hukum Berlalu Lintas Melalui

Pemahaman Terhadap Isi Undang-Undang No. 22 Tahun 2009 tentang Lalu Lintas dan Angkutan

Jalan, Jurnal Pendidikan Ilmu Sosial, Vol. 25, No. 2, Edisi Desember 2019.

Undang-Undang Nomor 22 Tahun 2009 tentang Lalu Lintas dan Angkutan Jalan.

http//:www.Pewarta Medan.com, 2019.

http//:www.Tribun Medan.com, 2019. 